\title{
Headache and Bruxing Behavior Types in Craniomandibular Disorders (Cmds) Patients
}

\author{
Tipos de Dores de Cabeça e Bruxismo em Pacientes com e sem Distúrbios Craniomandibulares
}

\section{Omar Franklin Molina', Marcus Geraldo Peixoto ${ }^{2}$, Nayene Leocádia Manzutti Eid ${ }^{3}$, Raphael Navarro Aquilino ${ }^{4}$, Rise Consolação Iuata Costa Rank}

\begin{abstract}
Objective. Assess headache and bruxism in Craniomandibular Disorders (CMDs) and non CMDs patients. Method. Clinical examination, questionnaires, headache criteria, severity of bruxism. Results. The prevalence of headache was $68.3 \%$ in the CMDs group and $51.4 \%$ in the non-CMDs group $(\mathrm{p}<0.04)$. Tension type $(\mathrm{TTH})=52.8 \%$ and combination headaches $=25.2 \%$ predominated in CMDs. Migraine was more prevalent in Non-CMDs $(21.1 \%)$ than in CMDs subjects (11.4\%). Severe bruxism predominated in the headache/CMDs group $=35 \%$ as compared to the non-headache/ CMDs group $=21 \%$, $(\mathrm{p}=0.08)$. We found a frequency of $29.3 \%$ extreme bruxism in the headache group and $7 \%$ in the non-headache group $(\mathrm{p}<0.0005)$. The frequencies of mild/moderate bruxism were about $28 \%$ in the TTH, $44.8 \%$ in the "other headaches" and $72 \%$ in the non-headache/CMDs groups. The frequencies of severe/extreme bruxism were $72.3 \%$ in the TTH, $55.2 \%$ in the "Other headaches", and $28 \%$ in the non- headache/CMDs groups( $\mathrm{p}=0.0001)$. Conclusion. Headache, TTH and combination headache were common in the CMDs group. Severe and extreme bruxism were more prevalent in the headache /CMDs group than in the "other headaches" and in the non/headache CMDs groups. Severe and extreme bruxism were more frequent in the TTH/CMDs group.
\end{abstract}

Keywords. Craniomandibular disorders, Headaches, Bruxism.

Citation. Molina OF, Peixoto MG, Eid NLM, Aquilino RN, Rank RCIC. Headache and Bruxing Behavior Types in Craniomandibular Disorders (Cmds) Patients.

\section{RESUMO}

Objetivo. Avaliar dor de cabeça e bruxismo em pacientes com e sem Distúrbios Craniomandibulares (DCMs). Método. Exame clínico, questionários, critérios para dores de cabeça e gravidade do bruxismo. Resultados. A prevalência de dor de cabeça foi de $68,3 \%$ no grupo com DCMs e de 51,4\% no grupo sem DCMs ( $<<0.04)$, sendo mais frequentes as de tensão muscular (DCT, 52,8\%) e combinada $(25,2 \%)$. Houve uma tendência a bruxismo grave no grupo dor de cabeça/DCMs (35\%) quando comparado com o grupo sem dor/ DCMs $21 \%$ ( $\mathrm{p}=0.08$ ). Verificamos uma freqüência de $29.3 \%$ de bruxismo extremo no grupo com dor de cabeça e $7 \%$ no grupo sem dor $(\mathrm{p}<0.0005)$. A freqüência de bruxismo grave foi de $29,3 \%$ no grupo com dor de cabeça e $7 \%$ no grupo sem dor de cabeça $(\mathrm{p}<0,0005)$. A frequencia de bruxismo leve/moderado foi de $28 \%$ no grupo DCT, $44.8 \%$ no grupo "outras dores de cabeça" e $72 \%$ no grupo sem dor de cabeça/CMDs respectivamente. As freqüências de bruxismo severo/ extremo foram $72,3 \%$ no grupo DCT, $55,2 \%$ no grupo "outras dores de cabeça" e 28\% no grupo "sem dores de cabeça/CMDs ( $\mathrm{p}=0,0001$ ). Conclusáo. Dores de cabeça (tensional e combinada), bruxismo grave e extremo estão associadas a DCMs.

Unitermos. Distúrbios craniomandibulares, Dores de cabeça, Bruxismo.

Citaçáo. Molina OF, Peixoto MG, Eid NLM, Aquilino RN, Rank RCIC. Tipos de Dores de Cabeça e Bruxismo em Pacientes com e sem Distúrbios Craniomandibulares.

\footnotetext{
This investigation was carried out at UNIRG-TO and supported by a Research Fund in Medical Sciences, Gurupi-TO, Brazil.

1. MDS, Certificated in Craniomandibular disorders, Post Doctoral in Orofacial Pain, Professor of Occlusion and Orofacial Pain, UNIRG, Dental School, Gurupi-TO, Brazil.

2. MDS, Ph.D in Orthodontics, Specialist in Orofacial Pain, Dean UNIRGTO, Gurupi-TO, Brazil.

3. MDS in Radiology, Post Doc in medical pathophysiology, UNICAMP, Brazil, Professor of Clinical Dentistry, UNIRG-TO, Gurupi-TO, Brazil.

4. MDS, Ph.D in Radiology, UNICAMP, Professor of Radiology, UNIRGTO, Brazil.

5. MDS, Doctoral Student, Dean School of Dentistry, UNIRG-TO, Gurupi-

TO, Brazil.
} 


\section{INTRODUCTION}

Research and clinical activity on chronic pain has been a major concern of clinicians and researchers in behavioral medicine. The most common form of head pain is tension type headache (TTH) described as a longstanding, continuous, dull, aching pain of variable intensity occurring in the temporal, frontal and sub-occipital regions ${ }^{1}$. Such headache is also described as mild to moderate, occurring either in episodes of variable duration or continuous (chronic form), bilateral, pressing, tightening, constricting, sometimes associated with nausea or vomiting and rarely with photophobia and phonophobia, usually lasting hours or days ${ }^{2}$. Episodic and chronic TTH may initiate in the forehead and temporal area and radiate to the occipital and sub-occipital zones of the head $^{3}$. TTH is a heterogeneous category and only some individuals demonstrate elevated muscle activity during a headache state. Bruxism is the excessive and involuntary habit of clenching and grinding the teeth ${ }^{4}$. Such behavior is also an oral phenomenon involving nocturnal/diurnal tooth clenching and/or grinding 5 . Craniomandibular Disorders (CMDs) is a collective term encompassing a number of clinical signs and symptoms of some disorders involving the masticatory muscles, temporomandibular joints (TMJs) and adjacent structures of the stomatognathic system ${ }^{6}$. Bruxism in the form of clenching or grinding may cause hyperactivity, fatigue and soreness of some masticatory muscles, activation of facial, head and cervical musculature causing facial, cervical and head pain ${ }^{7}$. There is a connection between bruxism, CMDs and headache and over-contraction of the jaw muscles may be the most common factor in $\mathrm{TTH}^{7}$. Headaches are a common symptom of CMDs in patients with oral jaw habits including bruxism ${ }^{8}$.

\section{LITERATURE REVIEW}

Patients presenting with severe diurnal and nocturnal bruxism are those who apply strong forces on the teeth during the night ${ }^{9}$, and when they have abnormal oral function they usually suffer from TTH, migraine and combination headach $\mathrm{e}^{10}$ and chronic clenching/grinding are probably some of the most important sustaining factors in TTH, which etiology is thought to be multi-factorial. Grinding the teeth can cause pain and clenching can lead to muscu- lar ischemia and fatigue. Parafunctional jaw habits are one cause of jaw fatigue as tooth grinding during 30 minutes induces facial pain that lasts for two days ${ }^{11}$. Biting with about $25 \%$ of maximal bite force impairs muscle blood flow $^{12}$, and thus, muscular hyperactivity causing ischemia, tenderness and pain are possible mechanisms in migraine and $\mathrm{TTH}^{10}$. Bruxing behavior may also be an important contributing factor for the development of trigger points in the head and neck which in turn causes and/or contributes to TTH and myofascial headache (MHA). TTH is thought to be the result of referred pain to the frontal/ temporal areas, from cervical trigger points ${ }^{4}$. One study ${ }^{10}$, evaluated migraine, TTH and combination headache patients and reported that most TTH individuals exhibited tenderness of the masticatory muscles thought to be related to muscle hyperactivity and oral jaw habits. Studies discussing teeth grinding or clenching during sleep as a source of headache problems are scarce and many patients are unaware of their night-time/daytime bruxing activity ${ }^{1}$. Waking state muscle activity inducing or associated with TTH includes any habitual behavior like tooth clenching or grinding and poor posture of the head and neck exhibited by a patient ${ }^{1}$. Sleeping state muscle activity or bruxism may contribute to headache disorders including TTH. For instance, masticatory muscle problems are reported to result from bruxism, strong and often rhythmic contractions during sleep ${ }^{13}$. The relationship found between frequent headaches in CMDs patients, fatigue of the jaw muscles, tenderness to palpation and frequent oral jaw habits, suggests that muscle disturbances related to oral jaw habits may be an underlying cause of headaches ${ }^{14}$.

Because the relationships between oral jaw habits and headache, specifically TTH are still obscure, the goals of this study are to elucidate the following questions:

1. Is the prevalence of headache high in CMD patients as compared to non CMD individuals?

2. Is TTH the most prevalent headache type in CMD and bruxing behavior subjects with headache?

3. What types of bruxing behavior predominate in individuals with tension type, "other headaches" and in non CMD individuals.

\section{METHOD}

Patients for this study were those referred consecu- 
tively for diagnosis and treatment of CMDs to the University of Gurupi, School of Dentistry in the period 20032008. There were 160 females (88.9\%) and 20 males $(11.1 \%)$ and the mean age of the group was about 33.3 years $(\mathrm{SD}=10.8$, range $14-67)$. Criteria to include patients as presenting CMDs included two of the following: A complaint of pain, actively seeking CMD treatment, joint noises, difficulties to perform active jaw movements, and tenderness to palpation. A combination of symptoms described above, better constitutes a CMD. Patients were evaluated comprehensively: establishing and obtaining a full description of the chief complaint including location, duration, frequency, intensity and quality, evaluating if the complaint was within the scope of CMDs, assessing muscle tenderness and trigger points by palpation, evaluation of jaw movements, use of diagnostic tests for internal joint derangements and trigger points in the cervical region, evaluating presence and severity of bruxing behavior and oral jaw habits using appropriate questionnaires, self report and clinical examination. Criteria for bruxing behavior are described as follows: 0-2 signs/symptoms, 3-5 signs/symptoms, 6-10 signs/symptoms, 11-15 signs/ symptoms and 16-24 signs/symptoms corresponded to no bruxism, mild, severe and extreme bruxing behavior, respectively. Because there are many sign and symptoms of bruxing behavior, a full range of severities can be assessed with such instrument. A simple questionnaire was used to detect pain complaints local and distant to the stomatognathic system. 37 individuals referred to the Dental School in the same period of time with a variety of complaints but with no characteristics of CMDs were used as a control group. Once we obtained clinical information and patients and controls responded to the self-report questionnaires, they were classified as presenting headache, non-headache, tension type headache, combination headache, myofascial headache, migraine, CMDs, no CMDs, no bruxism, mild, moderate, severe and extreme bruxing behavior. Criteria for different headache types (Tensiontype headache, Migraine and Myofascial headache) were delineated in a previous study ${ }^{15}$.

Criteria for combination headache were those of the National Headache Foundation ${ }^{16}$ :

Criteria for tension type headache: Headache described as bilateral, pain occurring in the temporal, frontal and occasionally in the occipital regions, pain described as dull, constant, pressure and constriction, presence of nausea more frequently than vomiting and pain described as mild or moderate more frequently than severe.

Criteria for migraine headache: Pain described as unilateral, severe, constant and always throbbing, pain increasing by physical effort and the throbbing characteristic observed more frequently during severe episodes of pain.

Criteria for combination headache: Pain described as unilateral or bilateral, unilateral episodes of pain described as throbbing, presenting with nausea, vomiting and visual disturbances, bilateral episodes of pain presenting the characteristics of tension- type headache and finally, patients' report of "two types of headaches".

Criteria for myofascial headache: Episodes of unilateral headache described as dull, aching, constant, pressure or tightness and without demonstrating the characteristics of migraine headache. Presence of cervical trigger points responsible for the predictable pattern of "headache". Kreisberg", contends that temporal and occipital headaches, may occur from trigger points in the trapezius muscle and are often misdiagnosed as "atypical migraine". Because this study was based on the retrospective review of CMDs patients' charts, the ethical committee of the Dental School approved this research project.

\section{Statistical analysis}

Fisher's exact test, trend analysis and Mann-Whitney tests were used to compare differences in the frequency of females, age and frequency of headaches and bruxing behavior types in headache, tension type headache, "other headache" and in non-headache individuals.

\section{RESULTS}

The results of this study are presented in Tables 1 through 4 .

Trend analysis comparing severe bruxism in the tension-type headache, "Other headache groups" and in the Non-headache/CMDS group, $\mathrm{p}=0.04$, indicating that the probability of finding severe bruxers increases from the Non-headache to the "Other headaches" and to the Tension-type headache group.

The same analysis was used for extreme bruxism in the same three groups. Because trend analysis showed a 
p value of about 0.0035 , it indicates that the likelihood of finding extreme bruxers increases from the Non-headache/CMD to the Other headaches" and to the Tensiontype headache group.

Table 1 demonstrates that the mean age of the group of 180 bruxers and CMD individuals was about 33.3 years $(\mathrm{SD}=10.8$, range $14-67)$.

Table 2 shows the frequencies of headache in 180 CMDs and in 37 non CMD subjects and the frequencies of headache types in 123 subjects with headache and bruxing behavior. The frequency of headache was about 68.3\% ( $\mathrm{n}=123)$ in the CMDs group and $51.4 \%(\mathrm{n}: 19)$ in the non CMDs group (chi square for independence $\mathrm{p}=0.04$ ), considered a significant difference. The frequencies of TTH, combination headache, myofascial head- ache and migraine were about 52.8\% ( $\mathrm{n}=65), 25.2 \%$ $(\mathrm{n}=31), 10.6 \%(\mathrm{n}=13)$, and $11.4(\mathrm{n}=14)$, respectively in the CMDs and bruxing behavior group with headache and $36.8 \%, 15.8 \%, 26.3 \%$, and $21.1 \%$, respectively in the group of non CMDs group with headache $(n=19)$. TTH (52.8\%) and combination headache (25.2\%) were the most frequent headache pains in the group of CMDs patients with headache. Of the 19 subjects with headache in the Non CMDs group ( $\mathrm{n}=37)$, TTH $(\mathrm{n}=7)$ and myofascial headache $(n=5)$ were the most frequent head pains.

Table 3 shows that the frequencies of mild, moderate, severe and extreme bruxism in the headache + CMDs group were about 13\% ( $n=16), 22.7 \%(n=28), 35 \%(n-$ 43) and $29.3 \%(n=36)$, respectively. The frequencies of mild, moderate, severe and extreme bruxing behavior in

Table 1

Demographic data in 180 CMDs and bruxing behavior subjects and in 37 non CMDs bruxers controls

\begin{tabular}{|c|c|c|c|c|c|}
\hline \multirow[b]{3}{*}{ Sex } & \multirow{2}{*}{\multicolumn{2}{|c|}{$\begin{array}{c}\text { CMD } \\
N=180\end{array}$}} & \multirow{2}{*}{\multicolumn{2}{|c|}{$\begin{array}{c}\text { Non CMD } \\
\mathrm{N}: 37\end{array}$}} & \multirow{3}{*}{ p-value } \\
\hline & & & & & \\
\hline & $\mathrm{n}$ & $\%$ & $\mathrm{n}$ & $\%$ & \\
\hline Males & 20 & 11,1 & 7 & 18,9 & \\
\hline Females & 160 & 88,9 & 30 & 81.1 & $0.27^{*}$ \\
\hline Totals & 180 & 100 & 37 & 100 & \\
\hline Mean age & & & & & $0.20^{* *}$ \\
\hline SD & & & & & \\
\hline Range & & & & & \\
\hline
\end{tabular}

* Fisher's exact test, $\mathrm{p}=0.27$. There was no difference in the frequency of females in the CMDs and Non-CMDs groups

** Mann-Whitney non parametric test, $\mathrm{p}=0.20$. A non significant difference in age in CMDs and controls non CMDs

Table 2

Headache prevalence in CMD and non CMD subjects and headache

\begin{tabular}{|c|c|c|c|c|c|}
\hline & \multicolumn{2}{|c|}{ CMDs subjects: 180} & \multicolumn{2}{|c|}{ Non CMDs subjects: 37} & \multirow{2}{*}{ p-value } \\
\hline & $\mathrm{n}$ & $\%$ & $\mathrm{n}$ & $\%$ & \\
\hline Headache & 123 & 68.3 & 19 & 51.4 & $0.04^{*}$ \\
\hline No headache & 57 & 31.7 & 18 & 48.6 & \\
\hline Totals & 180 & 100 & 37 & 100 & \\
\hline Tension headache & 65 & 52.8 & 7 & 36.8 & $0.05^{*}$ \\
\hline Combination headache & 31 & 25.2 & 3 & 15.8 & 0.21 \\
\hline Myofascial headache & 13 & 10.6 & 5 & 26.3 & 0.21 \\
\hline Migraine & 14 & 11.4 & 4 & 21.1 & 0.51 \\
\hline Totals & 123 & 100 & 19 & 100 & \\
\hline
\end{tabular}

*Fisher's exact test: A statistically significant difference when comparing the frequency of headache and tension headache in CMDs and controls. Such differences did not occur at random. 
the non-headache + CMDs group $(\mathrm{n}=57)$, were about $31.6 \%(\mathrm{n}=18), 40.4 \%(\mathrm{n}=23), 21 \%(\mathrm{n}=12)$ and $7 \%$ $(\mathrm{n}=4)$, respectively.

The frequency of mild bruxism was higher in the non headache + CMDs group (Fisher's exact test $\mathrm{p}<0.004$ ), very significant). The difference in the frequencies of moderate bruxism in the headache $(22.7 \%)$ and non headache + CMDs group (40.4\%) was also significant (Fisher's exact test $\mathrm{p}<0.02)$. The difference in the frequencies of severe bruxism in the headache + CMDs (35\%) and non headache + CMDs group (21\%) was not statistically significant
(Fisher's exact test $\mathrm{p}>0.08$ ). The difference in the frequencies of extreme bruxing behavior in the headache + CMDs $(29.3 \%)$ and non-headache group + CMDs (7\%) was statistically and extremely significant (Fisher's exact test $\mathrm{p}<0.0005)$.

Table 4 shows the frequencies of bruxism subtypes in 65 TTH individuals, 58 individuals with "Other headaches", and 57 subjects with no headaches and CMDs.

The frequencies of mild bruxism in these subgroups were about $9.2 \%(\mathrm{n}=6), 17.2 \%(\mathrm{n}=10)$ and $31.6 \%(n=18)$ respectively. When the frequency of mild

Table 3

Frequencies of bruxing behavior types in subjects with CMDs +headache and CMDs/no headache

\begin{tabular}{|c|c|c|c|c|c|c|}
\hline \multirow[b]{3}{*}{ Bruxing type } & \multirow{2}{*}{\multicolumn{2}{|c|}{$\begin{array}{c}\text { Headache + CMDs } \\
\mathrm{N}=123\end{array}$}} & \multirow{2}{*}{\multicolumn{2}{|c|}{$\begin{array}{c}\text { No Headache + CMDs } \\
\text { N:57 }\end{array}$}} & \multirow[b]{3}{*}{$\mathrm{p}$ value } & \multirow[b]{3}{*}{ Significant } \\
\hline & & & & & & \\
\hline & $\mathrm{n}$ & $\%$ & $\mathrm{n}$ & $\%$ & & \\
\hline Mild & 16 & 13 & 18 & 31.6 & 0.004 & Yes* \\
\hline Moderate & 28 & 22.7 & 23 & 40.4 & 0.02 & Yes ** \\
\hline Severe & 43 & 35 & 12 & 21 & 0.08 & $\mathrm{No}^{* * *}$ \\
\hline Extreme & 36 & 29.3 & 4 & 7 & 0.0005 & Yes**** \\
\hline Totals & 123 & 100 & 57 & 100 & & \\
\hline
\end{tabular}

*Fisher's exact test $\mathrm{p}<0.004$ : The frequency of mild bruxism was higher in the non-headache group and the difference was statistically significant.

**Fisher's exact test $\mathrm{p}<0.02$ : There were more moderate bruxers in the non

headache than in the headache group and the difference was statistically significant.

***Fisher's exact test $\mathrm{p}<0.08$ : The difference in prevalence was not significant

****Fisher's exact test $\mathrm{p}<0.0005$ : Extreme bruxers were more prevalent in the headache group than in the non-headache and the difference was very significant

Table 4

Table IV: Bruxing behavior types in individuals with TTH +CMDs and Other headaches + CMDs" and No-Headache + CMDs

\begin{tabular}{|c|c|c|c|c|c|c|}
\hline \multirow[b]{3}{*}{ Mild } & \multirow{2}{*}{\multicolumn{2}{|c|}{$\begin{array}{c}\begin{array}{c}\text { Tension type } \\
\text { headache+CMDs }\end{array} \\
\mathrm{N}: 65\end{array}$}} & \multirow{2}{*}{\multicolumn{2}{|c|}{$\begin{array}{c}\text { Other headaches+CMDs } \\
\text { N:58 }\end{array}$}} & \multirow{2}{*}{\multicolumn{2}{|c|}{$\begin{array}{c}\text { No headaches+CMDs } \\
\mathrm{N}: 57 \\
\end{array}$}} \\
\hline & & & & & & \\
\hline & $\mathrm{n}$ & $\%$ & $\mathrm{n}$ & $\%$ & $\mathrm{~N}$ & $\%$ \\
\hline Mild & 6 & 9.2 & 10 & 17.2 & 18 & $31.6^{*}$ \\
\hline Moderate & 12 & 18.5 & 16 & 27.6 & 23 & $40.4^{* *}$ \\
\hline Severe & 27 & 41.5 & 16 & 27.6 & 12 & $21^{* * *}$ \\
\hline Extreme & 20 & 30.8 & 16 & 27.6 & 4 & $7.0^{* * * *}$ \\
\hline Totals & 65 & 100 & 58 & 100 & 57 & 100 \\
\hline
\end{tabular}

*Mild bruxism: Tension-headache versus "Other headache" group

Tension-headache versus No headache/CMD group

$\mathrm{p}=0.28$

** Moderate bruxism: Tension-headache versus "Other headache" group Tension-headache versus No-headache/CMD group

***Severe bruxism: Tension-headache versus "Other headaches" group $\mathrm{p}=0.002$

$\mathrm{p}=0.28$

$\mathrm{p}=0.0009$

Tension-headache versus No-headache/CMD group $\quad \mathrm{p}=0.01$

$\mathrm{p}=0.13$

****Extreme bruxism: Tension-headache versus "Other headaches" group $\quad \mathrm{p}=0.84$ Tension-headache versus No-headache/CMD" group $\mathrm{p}=0.001$ 
bruxism was compared in the groups presenting TTH and "other headaches", the difference was not statistically significant $(\mathrm{p}=0.28)$. When the groups presenting TTH and no headache + CMDs, were compared regarding mild bruxism, the difference was very significant (Fischer exact test $\mathrm{p}=0.002$ ).

The frequencies of moderate bruxism in these 3 groups were about $18.5 \%(n=12), 27.6 \%(n=16)$ and $40.4 \%(n=23)$, respectively. When such frequencies were compared in the TTH group and the "Other headaches" group, the difference was not statistically significant $(\mathrm{p}=0.28)$. When frequencies in moderate bruxism were compared in the groups presenting TTH (18.5\%) and no headache/CMDs (40.4\%), the difference in frequency was very significant $(\mathrm{p}=0.0009)$.

The frequency of severe bruxism in the TTH group was about $41.5 \%, 27.6 \%$ in the "other headaches" group and $21 \%$ in the non-headache/CMD. The difference from the TTH to the "Other headaches" group was not significant (Fischer's exact test $\mathrm{p}=0.13$ ), but it was different and statistically significant from the TTH to the non-headache/CMD group (Fischer's exact test $\mathrm{p}=0.01$ ).

The frequency of extreme bruxism was about $30.8 \%$ in the TTH group, $27.6 \%$ in the "Other headache" group, and $7 \%$ in the non-headache/CMD group. This difference was not statistically significant from the TTH to the "Other headaches" group (Fisher's exact test $\mathrm{p}=0.84$ ), but it was very significant from the TTH to the non-headache/CMD group (Fisher's exact test $\mathrm{p}=0.001$ ).

\section{DISCUSSION}

\section{The prevalence of headache was high in CMD patients}

$68.3 \%$ of the population of CMD and bruxing behavior presented with a complaint of headache. Bruxing behavior is a frequent cause of headache in the frontal, temporal, retro-orbital, vertex, face and occipital regions. Fatigue of the jaw muscles and clenching/grinding are common complaints in patients with mandibular dysfunction and headaches ${ }^{1}$. Because over-contraction of the jaw muscles is a frequent cause of $\mathrm{TTH}^{15}$, and many bruxers in this study were headache free, it may be that frequency and intensity of these oral jaw habits are more important as etiologic and/or sustaining factors in $\mathrm{CMD} /$ headache than in $\mathrm{CMD} /$ non-headache individuals. This assump- tion is supported by the observation of 4 different groups of bruxers in this and other studies ${ }^{17}$. The results of the current investigation are also in accordance with another research ${ }^{18}$, reporting that headache was frequent in CMD and bruxing behavior patients and predominated in the groups presenting moderate and severe bruxing behavior.

\section{TTH was the most prevalent headache in CMD and bruxing behavior subjects}

The frequency of TTH in the whole group of 180 CMD and bruxing behavior subjects was about 36.1\% and $52.8 \%$ specifically in the group of $123 \mathrm{CMD}$ and bruxers that reported headaches. The frequency of TTH in the non CMD group was about 36.8\% TTH was the most frequent headache in both CMDs and non CMD groups. One investigation ${ }^{19}$, evaluated chronic daily headache and reported a frequency of $57 \%$ bilateral pain in 37 patients having mild pain and a frequency of 39\% bilateral pain in 75 patients reporting severe headache. However, in that study, researchers did not report frequency of bruxism and it was likely that combination pain subjects were present in the group of individuals with "bilateral pain". One study ${ }^{20}$ evaluated some clinical features of the acute migraine attack and reported a frequency of about 42\% "pressing headache" and 44\% "bilateral pain". Both frequencies are similar to the prevalence of $52.8 \%$ TTH found in the group of headache patients in this study. Both "pressing" and "bilateral" are TTH characteristics, but they may also be reported in combination headache patients and even in cases of bilateral myofascial pain referred to the head. The frequency of $52.8 \%$ of TTH reported in the current study in the CMD and headache group is different as compared to that reported in other study $^{8}$ "indicating that TTH accounts for $90 \%$ of all headache pains". However, it is likely that patients presenting combination headache may have been included in such frequency.

One investigation $^{21}$, evaluated CMDs in headache patients and reported a frequency of 56\% bilateral headache/facial pain which is very similar to the results reported in the current research. Furthermore, all our patients were also CMDs, most had facial pain and "bilateral" was included as a feature of TTH. Because in the current study, CMDs and bruxing behavior subjects demon- 
strated the highest frequency of TTH, the results of this study are in line with another research ${ }^{22}$ reporting that "most people with headaches have episodic TTH which is sporadic and of mild intensity". One investigation ${ }^{3}$, evaluated CMD and non CMD individuals reporting a lower frequency (36\%) of TTH in the CMD group, but only $57 \%$ of individuals in that study were bruxers, thus, decreasing the frequency of TTH. It may be that when severe and extreme bruxism is present in some groups, it is more likely to find a higher frequency of TTH. Subjects reporting frequent clenching and with almost no wear facets may have severe CMDs symptoms including headaches ${ }^{23}$. Persistent oral jaw habits increase tension in the masticatory muscles and result in pain ${ }^{24}$. Prolonged jaw muscle hyperactivity is correlated with the symptoms of jaw dysfunction and the greater the level of nocturnal EMG activity, the more likely it is to have sign/symptoms of jaw dysfunction" ${ }^{25}$. Sleeping state muscle activity (bruxism) in the form of strong and often rhythmic contractions of the jaw muscles may contribute to headache ${ }^{1}$.

\section{Severe and extreme bruxing behavior predominated in headache individuals}

All subjects in this study were bruxers, but $31.7 \%$ were headache-free. We found that mild (31.6\%) and moderate bruxing behavior (40.4\%) were more frequent in non-headache than in headache individuals $(13 \%$ and $22.75 \%$ respectively). On the other hand, severe and extreme bruxing behavior occurred more frequently in headache $(34.9 \%+29.3 \%=64.2 \%)$ than in nonheadache individuals $(21 \%+7 \%=28 . \%$, respectively. The frequency of combined severe and extreme bruxing behavior $(64.2 \%)$ in the headache + CMD group was higher as compared to the non-headache + CMD group $(16=28 \%)$ and the difference was extremely significant (Chi-square test $\mathrm{p}=0.0001$ ). Comparing only extreme bruxing behavior, we found that such bruxism predominated in headache $(29.3 \%)$ as compared to non-headache subjects $(7 \%)$ and the difference was extremely significant (Fisher's exact test $\mathrm{p}<0.005$ ). Because sleeping state muscle activity or bruxism, contributes to headache disorders $^{1}$, it is more likely that headache be associated with severer forms of bruxing behavior. Supporting this point of view, an investigation ${ }^{26}$, evaluated destructive, sleep and depressed bruxism and even though the groups were small, researchers reported different number of symptoms and intensity of pain. The destructive group presented with more severe bruxism including jaw pain and headaches. Bruxism is related to muscular contractions usually bilatera ${ }^{26}$ and when such forces are great and long enough, they may cause headaches and pain upon rising. Because in one study ${ }^{27}$, the reported frequency of bruxism was significantly higher among migraineurs, it is likely that more severe bruxism is more important to cause headache than its sole presence. In one study ${ }^{14}$, habits of oral parafunctions such as grinding and clenching were related to the frequency of headaches. It may be that a combination of oral jaw habits and more severe bruxism are correlated with headache frequency and intensity. In other words, less severe and less frequent bruxism and lesser number of oral jaw habits are expected to occur in non- headache subjects.

\section{Severe and extreme bruxing behavior predominated in TTH subjects}

Interesting to note is that in the $\mathrm{TTH}$ group, $47=72.3 \%$ subjects demonstrated severe and extreme bruxing behavior, but 18 or $27.69 \%$ presented with mild and moderate bruxism. When pooled mild and moderate bruxism in TTH (27.7\%) and in "Other headaches" (55.2\%) were compared, mild and moderate types were more frequent in "Other headaches" and the difference was statistically very significant (Fisher's exact test $\mathrm{p}<0.003)$. When pooled severe and extreme bruxism were compared in TTH (72.3\%) and in the "Other headaches" group (55.2\%), we found that severe and extreme bruxing behavior were more prevalent in TTH subjects and the difference $(p=0.07)$ almost reached significance. This trend to observe severer forms of bruxing behavior in TTH and CMD individuals, should be further elucidated.

Because Chi-square trend analysis was used to compare the frequency of severe bruxism in the TTH, "Other headache" and in "non-headache/CMD" groups, and yielded a p-value $=0.04$, such a result, indicated that the probability of finding severe bruxism increased from the non-headache/CMD to the "Other headache" and to the TTH group. The same analysis was used to compare extreme bruxism in the three groups. Because 
such analysis yielded a $\mathrm{p}$ value $=0.003$, it indicated that extreme bruxism is more likely to be found in those presenting TTH. Such results are not actually surprising, as sleeping state muscle activity can contribute to headache disorders ${ }^{1}$. Nocturnal bruxism is more likely to be bilateral and intense loading associated to severe and extreme bruxing behavior is more likely to cause TTH. This is not surprising as sustained muscle activity of the jaw elevators during function may cause more intense headache pain. Because TTH was also observed in the mild and moderate bruxing behavior groups, it may be that intense loading is not a unique characteristic of TTH. It is likely that a combination of bruxing behavior, oral jaw habits and trigger points in the cervical musculature is also associated with TTH. This assumption has support at least in part in one study ${ }^{28}$ suggesting that TTH is a heterogeneous category where only some individuals demonstrate elevated muscle activity during non headache and headache states. Additionally, sustained tonic contraction of muscles may possibly induce trigger points ${ }^{29}$.

The results of the current study are also in line with one investigation ${ }^{3}$, reporting a frequency of $24 \%$ bruxism and TTH as compared to $11 \%$ bruxism and no headache. This difference indicates that bruxism is more likely to be associated with headache, specifically with TTH. The frequency of TTH and severer bruxism was higher as compared to the frequency of TTH and a milder form of bruxism. It may be that another factors including hostility, anger, somatization and even hysteria, are more common contributory factors in severer bruxism and TTH. Therefore, the higher the scores of those psychological factors, the higher the frequency of both TTH and bruxism. One research ${ }^{30}$, noted that compared with healthy controls, TTH patients were more likely to demonstrate inability to express emotions, a characteristic of individuals with somatization. Furthermore, in one study ${ }^{31}$, chronic daily headache was also associated with hysterical traits. Both anger and somatization are also present in bruxing behavior. It may be that the higher the level of anger, resentment and difficulties to express psychological conflict, the higher the likelihood of resulting in both TTH and bruxism.

Limitations of this study: Some findings in the current study are worthy of mention: The higher preva- lence of headache in CMDs patients as compared to nonCMDs subjects, a higher frequency of TTH in headache and CMDs patients, the higher frequency of severe and extreme bruxing behavior in headache as compared to non-headache individuals, and in TTH subjects as compared to individual in the "Other headaches" and no headaches + CMD groups. However, because of the cross sectional nature of this study, any potential conclusion should be subjected to further scrutiny. Replicating this study in the same clinical and epidemiological conditions and/or performing longitudinal investigations to further substantiate the results observed in the current investigation, is highly recommended.

\section{CONCLUSIONS}

Based on the results of this study and backed by the literature, we conclude that the frequency of headache was high in patients with CMDs and bruxism, TTH and combination headache were more prevalent in CMDs than in non-CMD individuals, mild and moderate bruxism occurred more frequently in non-headache than in the headache group, extreme bruxism was significantly more prevalent in the headache than in the nonheadache group, severe and extreme bruxism were significantly more prevalent than mild and moderate bruxism in TTH individuals and that such bruxing behavior types were significantly more prevalent in the TTH group than in the "Other headaches" and in the non-headache + CMD groups.

\section{REFERENCES}

1.Clark GT, Sakai S, Merrill R, Flack VF, McArthur D, McCreary C. Waking and sleeping temporalis EMG levels in tension type headache. J Orofac Pain 1997;11:298-305.

2.Olesen J. Clinical and pathophysiological observations in migraine and tension type headache explained by integration of vascular, supraspinal and myofascial inputs. Pain 1991;46:125-32.

http://dx.doi.org/10.1016/0304-3959(91)90066-7

3.Molina OF, dos Santos J, Nelson, Grossman, E. Prevalence of modalities of headaches and bruxism among patients with craniomandibular disorders. J Craniomand Pract 1997;15:314-29.

4.Pingitore G, Chroback V, Petrie J. The social and psychological factors of bruxism. J Prost Dent 1991;65:443-6.

http://dx.doi.org/10.1016/0022-3913(91)90240-W 
5.Boutros NN, Montgomery MT, Nishioka G, Hatch JP. The effects of severe bruxism on sleep architecture: A preliminary report. Clin Electroenceph 1993;24:59-62.

6.Molina OF, dos Santos J. Hostility in TMD/Bruxism patients and controls: A clinical comparison study and preliminary results. J Craniomand Pract 2002;20:282-8.

7.Kreisberg MK. Headache as a symptom of Craniomandibular Disorders I: Pathophysiology. J Craniomand Pract 1986;4:134-49.

8.Kemper JT, Okeson JP. Craniomandibular disorders and headaches. J Prost Dent 1983;49:702-5.

http://dx.doi.org/10.1016/0022-3913(83)90400-6

9.Nishigawa K, Bando E, Nakano M. A quantitative study of bite force during sleep bruxism. J Oral Rehab 2001;28:485-91.

http://dx.doi.org/10.1046/j.1365-2842.2001.00692.x

10.Lous I, Olesen J. Evaluation of pericranial tenderness and oral function in patients with common migraine, muscle contraction headache and combination headache. Pain 1982; 12:385-93.

http://dx.doi.org/10.1016/0304-3959(82)90183-X

11.Christensen LV. Jaw muscle fatigue induced by experimental tooth clenching in man. J Oral Rehab 1981;8:27-36.

http://dx.doi.org/10.1111/j.1365-2842.1981.tb00515.x

http://dx.doi.org/10.1111/j.1365-2842.1981.tb00472.x

12.Rasmussen OC, Bonde-Petersen F, Christensen LV. Blood flow in human mandibular elevators at rest and during controlled biting. Archs Oral Biol 1977;22:539-43.

http://dx.doi.org/10.1016/0003-9969(77)90052-8

13.Glaros AB, Rao SM. Bruxism: A critical review. Psychol Bull 1977;84:767-81. http://dx.doi.org/10.1037/0033-2909.84.4.767

14.Wänman A, Agerberg GE. Headache and dysfunction of the masticatory system in adolescents. Cephalalgia 1986;6:247-55.

http://dx.doi.org/10.1046/j.1468-2982.1986.0604247.x

15.Molina OF, dos Santos J, Nelson SJ, Grossman E. Prevalence of modalities of headaches and bruxism among patients with craniomandibular disorders. J Craniomand Pract 1997;15:314-29.

16.National Headache Foundation: Coexisting migraine and tension-type headache 2009, p.1-2.

17.Molina OF, Tavares GP, Aquilino RN, Rank R, Coelho SZ, César EW, et al. Depression, pain, and site: a clinical comparison study in mild, moderate, severe and extreme bruxers. Rev Neurocienc 2007;15:09-16.

18. Molina OF, dos Santos J, Nelson SJ, Nowlin T. A clinical study of specific sign and symptoms of CMD in bruxers classified by the degree of severity. J Craniomand Pract 1999;17:268-79.
19.Spierrings EL, Ranke A, Schroever M, Honkoop PC. Chronic daily headache: A time perspective. Headache 2000;40:306-10.

http://dx.doi.org/10.1046/j.1526-4610.2000.00045.x

20.Olesen J. Some clinical features of the acute migraine attack: An analysis of 750 patients. Headache 1978;18:268-71.

http://dx.doi.org/10.1111/j.1526-4610.1978.hed1805268.x

21.Schökker RP, Hansson TL, Ansink BJ. Craniomandibular disorders in headache patients. J Craniomand Dis Facial Oral Pain 1989;3:72-4.

22.Benseñor IM, Tófoli LF, Andrade L. Headache complaints associated with psychiatric co-morbidity in a population based sample. Braz J Med Biol Res 2003;26:1425-32.

23.Kampe T, Tagdae T, Bader G, Edman, G, Karlsson S. Reported symptoms and clinical findings in a group of subjects with longstanding bruxing behavior. J Oral Rehab 1997;24:581-7.

http://dx.doi.org/10.1111/j.1365-2842.1997.tb00377.x http://dx.doi.org/10.1046/j.1365-2842.1997.00540.x

24.GramlingSE, Nebblett J, Graysson R. Temporomandibulardisorders: Efficacy of an oral habit reversal treatment program.J Behav Exp Psychiat 1996;27:245-55. http://dx.doi.org/10.1016/S0005-7916(96)00027-4

25.Clark GT, Beemsterboer PL, Rugh JD. Nocturnal masseter muscle activity and the symptoms of masticatory dysfunction. J Oral Rehab 1981;8:279-86. http://dx.doi.org/10.1111/j.1365-2842.1981.tb00502.x

26. Ware JC, Rugh JD. Destructive bruxism: Sleep stage relationships. Sleep 1988;11:172-81.

27.Steele JG, Lamey PG, Sharkey SW . Occlusal abnormalities, pericranial and joint tenderness and tooth wear in a group of migraine patients. J Oral Rehab 1991;18:453-8.

http://dx.doi.org/10.1111/j.1365-2842.1991.tb01690.x

28.Philips C, Hunter M. The treatment of tension headache. EMG abnormality and relaxation. Behav Res Ther 1981;19:499-507.

http://dx.doi.org/10.1016/0005-7967(81)90076-0

29.Jensen K, Bülow P, Hansen H. Experimental tooth clenching in common migraine. Cephalalgia 1985;5:245-51.

http://dx.doi.org/10.1046/j.1468-2982.1985.0504245.x

30.Yücel B, Kora K, Ozyalçin J, Alcaçar N. Depression, automatic thoughts, alexythimia and assertiveness in patients with tension headaches. Headache 2002;42:194-9.

http://dx.doi.org/10.1046/j.1526-4610.2002.02051.x

31.Mongini F, Ibertis F, Barbalonga E, Raviola F. MMPI-2 profiles in chronic daily Headache and the relationship to anxiety levels and accompanying symptoms. Headache 2000;40:466-72.

http://dx.doi.org/10.1046/j.1526-4610.2000.00070.x 